\title{
Effect of Intramammary Escherichia coli Endotoxin in Early- vs. Late-Lactating Dairy Cows
}

\author{
T. Lehtolainen, S. Suominen, T. Kutila, and S. Pyörälä \\ Department of Clinical Veterinary Science, Faculty of Veterinary Medicine, \\ University of Helsinki, FIN-04920 Saarentaus, Finland
}

\begin{abstract}
We investigated the differences in the effect of intramammarily infused endotoxin for cows in early (EL) and late (LL) lactation. In this crossover study, nine cows were challenged twice with $100 \mu \mathrm{g}$ of intramammarily infused Escherichia coli 0111:B4 LPS, each cow serving its own control. Systemic and local signs were recorded throughout the experiment to assess the severity of each cow's response. Daily milk yield and indicators of inflammation in blood and milk were also recorded. The response was significantly more severe in the EL period. Before the challenge, milk yield and serum free fatty acid concentration were higher and serum urea concentration lower in EL compared with LL cows. No significant differences were present in other parameters. After the challenge, milk SCC and leukocyte function, measured as chemiluminescence, increased, more markedly in EL. Blood neutrophil content varied from neutropenia to neutrophilia. Simultaneously with neutropenia, the function of neutrophils increased in LL but decreased in EL. Serum cortisol peaked $4 \mathrm{~h}$ after challenge in both groups. In conclusion, endotoxin challenge resulted in more severe response in EL. During that time cows also had impaired neutrophil function postchallenge.
\end{abstract}

(Key words: endotoxin, mastitis, dairy cow, lactation stage)

Abbreviation key: ASAT = serum aspartate aminotransferase activity, $\mathbf{A U}=$ arbitrary units, $\mathbf{C L}=$ chemiluminescence, $\mathbf{P C}=$ postchallenge, $\mathbf{P M N}=$ polymorphonuclear leukocytes, $\mathbf{W B C}=$ white blood cell count.

\section{INTRODUCTION}

Coliform mastitis, mostly caused by Escherichia coli, is a common disease in lactating dairy cows. The severity of the disease varies from mild to very severe, fatal

Received: May 23, 2002

Accepted: December 17, 2002

Corresponding author: T. Lehtolainen; E-mail: tanja.kaipainen@ helsinki.fi. forms. Cows can be divided into severe and mild responders by the intensity of general and local clinical signs, changes in milk's appearance, and loss of milk production during mastitis (Pyörälä et al., 1994; Dosogne et al., 1997). The clinical response and outcome of the disease vary according to the stage of lactation (Hill et al., 1979; Pyörälä and Pyörälä, 1998). Peracute $E$. coli mastitis with severe clinical signs most frequently occurs during the periparturient period and early lactation (Hill et al., 1979; Pyörälä and Pyörälä, 1998; Menzies et al., 2000). Physiologic stress around parturition and metabolic diseases may be associated with the susceptibility of periparturient cows to coliform mastitis (Suriyasathaporn et al., 2000).

The most important factor in intramammary defense against invading pathogens is polymorphonuclear leucocytes (PMN) (Burvenich et al., 1994). Their low initial numbers, maturity, and poor function in blood (Dosogne et al., 1997) as well as low SCC in milk (Shuster et al., 1996) correlate negatively with the severity of induced E. coli mastitis. In the postpartum period, the numbers of circulating PMN in blood are low (Kehrli et al., 1989; Zerbe et al., 2000), and their diapedesis into the infected quarters (Hill et al., 1979) and phagocytocis (Kehrli et al., 1989; Hoeben et al., 2000b; Mehrzad et al., 2001b) are impaired compared with later lactation. Hyperketonemia is fairly common during early lactation (Jorritsma et al., 2001) and may be one reason for decreased functions of PMN (Suriyasathaporn et al., 2000; Zerbe et al., 2000).

The aim of this study was to compare cows' response to endotoxin challenge in early and late lactation. Most studies have used different groups of cows to study variation of response over time in $E$. coli or endotoxin models. Because the response of individual cows to $E$. coli varies (Dosogne et al., 1997), but one cow's response tends to follow the same pattern on different occasions (Hirvonen et al., 1999), we used a crossover design to avoid the effects of interindividual variation (Pyörälä et al., 1994).

\section{MATERIALS AND METHODS}

\section{Animals and Endotoxin Challenge}

Ten clinically healthy Finnish Ayrshire cows participated. Two of the cows were primiparous and seven 
multiparous (two to four lactations). Cows were fed good quality silage and hay freely, and concentrate was given twice daily. The cows were milked twice a day at 6 a.m. and 5 p.m., and their milk yield was 17 to $38 \mathrm{~kg}$ per day in early lactation, and 5 to $19 \mathrm{~kg}$ per day in late lactation. All the cows were free from mastitis pathogens and had low SCC in their milk ( $<150000$ cells $/ \mathrm{ml})$. A crossover design was used; each cow was challenged twice, in the early lactation period 6 to $15 \mathrm{~d}$ of lactation, and in the late lactation period 137 to $77 \mathrm{~d}$ before the next parturition. Cows were randomly allocated into two groups; one group was challenged in the early lactation period, and the other group in the late lactation period for the first time. One cow had to be excluded, as it did not conceive.

Cows were infused after the morning milking into one hind quarter with $100 \mu \mathrm{g}$ of Escherichia coli 0111:B4 lipopolysaccharide B (Bacto, Difco Laboratories Inc., Detroit, MI) diluted into $5 \mathrm{ml}$ of sterile $\mathrm{NaCl}$. The same quarter was used at both challenges. The contralateral quarter was used as a control quarter.

The Ethics Committee of the Faculty of Veterinary Medicine, Helsinki, Finland, approved the study protocol.

\section{Clinical Examination and Sampling}

Systemic and local signs were recorded throughout the experiment. Systemic signs included general disposition, heart rate, rectal temperature, and appetite; local signs included swelling, temperature, and pain in the udder. Milk's appearance in the challenged quarter was also recorded. Systemic and local signs and milk appearance were scored from 1 to 3 , using also half numbers. In this scoring system, 1 resembled normal and 3 severe reaction, meaning systemically rectal temperature $>40.5$, anorexia and depression, locally severe swelling and pain into udder, and milk appearance changed to watery or pus-like (Pyörälä et al. 1994). The response-parameter was formed by calculating the average of these scores. This parameter is handled as continuous parameter and it fits well to the normal distribution curve. Severity of the response was assessed; $<2$ was classified as mild, $>2$ but $<3$ as moderate, and 3 as severe response. Total milk yield was recorded for each cow at both milking times and the 24-h milk yield was calculated.

Milk samples for the determination of SCC and milk NAGase activity were collected from the challenged and control quarters of each cow at $0,2,4,8,12,24,32,48$, and $72 \mathrm{~h}$. Blood samples for hematological and blood chemistry analyses were collected from the jugular vein in EDTA and serum tubes at the same timepoints. Milk and serum samples were stored frozen at $-21^{\circ} \mathrm{C}$.

\section{Analytical Methods}

Milk SCC was measured with a Fossomatic instrument (Foss Electric, Hillerød, Denmark) and from samples with clots and flakes with a Coulter Counter particle counter (Coulter Electronics Ltd., Northwell, England) (IDF, 1991). SCC values were measured with the Coulter Counter at 4, 8, and $24 \mathrm{~h}$, and at other times with the Fossomatic. Values over 15 million were recorded as 15 million. Milk NAGase activity was measured using a commercial Milk NAGase kit (Applied Diagnostics Corporation, Helsinki, Finland) (Mattila and Sandholm, 1986).

Hematological parameters [packed cell volume (PCV), hemoglobin, total and differential leukocyte count] were determined within $2 \mathrm{~h}$ of sampling using an automated multiparameter analyzer with software for animal samples (CELL-DYN 3700 System, ABBOTT Diagnostic Division, ABBOTT Park, IL).

PMN phagocytocis and respiratory burst in blood and milk was determined as zymosan-induced chemiluminescence (CL) as described earlier (Lilius et al., 1984; Lojek et al., 1997). Briefly, $20 \mu \mathrm{l}$ of luminol (10 mM), $25 \mu \mathrm{l}$ of opsonized zymosan ( $20 \mathrm{mg} / \mathrm{ml}), 180 \mu \mathrm{l}$ of HBSS (0.1\% gelatin), and $25 \mu \mathrm{l}$ of EDTA blood (1:200 dilution) or milk (1:1000 dilution) were pipetted into the wells of a microtiter plate and the CL was measured at $37^{\circ} \mathrm{C}$ for 40 min with a luminometer (Luminoskan, Labsystems, Helsinki, Finland). The samples were analyzed in triplicate within $2 \mathrm{~h}$ of sampling. The highest CL value during the 40 -min measuring time was considered to be the CL value of that timepoint. The value was divided by the number of PMN in blood or the number of somatic cells in milk at that time to obtain the CL of one cell. Serum cortisol levels were measured by radioimmunoassay (Coat-A-Count Cortisol, Diagnostic Product Corporation, Helsinki, Finland). Serum urea and creatinine were measured by the enzymatic kinetic method (Fabiny and Ertigshausen, 1971; Gutmann and Bergmeyer, 1974) using an automated analyzer (KONE Pro, ThermoClinical Labsystems, Espoo, Finland). Another automated analyzer (KONE Specific, ThermoClinical Labsystems, Espoo, Finland) was used to assess serum aspartate aminotransferase (ASAT) activity (Scandinavian Society for Clinical Chemistry and Clinical Physiology, 1974) and FFA concentration (Waco Chemicals GmbH, Neuss, Germany). The KONE Lab-Microlyte $3+2$ (ThermoClinical Labsystems, Espoo, Finland) analyzer was used to determine serum $\mathrm{Ca}^{2+}$.

\section{Statistical Methods}

The data were analyzed using mixed linear model approach (Lindsay, 1993). Where plausible, two different models were fitted to the data: 
Table 1. Initial values of parameters studied in nine dairy cows in early (EL) and late (LL) lactation.

\begin{tabular}{|c|c|c|c|c|}
\hline & \multicolumn{2}{|c|}{ EL } & \multicolumn{2}{|c|}{ LL } \\
\hline & Average & SD & Average & SD \\
\hline Temperature $\left({ }^{\circ} \mathrm{C}\right)$ & 38.6 & 0.20 & 38.7 & 0.37 \\
\hline Heart frequency $(/ \mathrm{min})$ & 83 & 13.6 & 82 & 11.2 \\
\hline Milk yield (kg/24 h) & $27.7 * *$ & 6.2 & 13.8 & 4.6 \\
\hline $\mathrm{SCC}\left(\times 10^{3} / \mathrm{ml}\right)$ & 37 & 29.4 & 83 & 163.9 \\
\hline NAGase $\left(\mathrm{AU}^{1}\right)$ & 22 & 6.7 & 15 & 15.7 \\
\hline $\mathrm{WBC}^{2}\left(\times 10^{6} / \mathrm{ml}\right)$ & 7.98 & 1.49 & 7.83 & 1.67 \\
\hline Neutrophils $\left(\times 10^{6} / \mathrm{ml}\right)$ & 3.53 & 1.33 & 3.05 & 1.01 \\
\hline Lymphocytes $\left(\times 10^{6} / \mathrm{ml}\right)$ & 3.06 & 0.58 & 3.48 & 0.81 \\
\hline Hematocrit (\%) & 34.7 & 1.6 & 32.6 & 2.9 \\
\hline $\mathrm{Ca}^{2+}(\mathrm{mmol} / \mathrm{l})$ & 1.31 & 0.13 & 1.28 & 0.09 \\
\hline $\operatorname{ASAT}^{3}(\mathrm{u} / \mathrm{l})$ & 89 & 16.7 & 73 & 20.2 \\
\hline Urea $(\mathrm{mmol} / \mathrm{l})$ & $3.6^{*}$ & 0.71 & $4.6^{*}$ & 0.61 \\
\hline Creatine $(\mu \mathrm{mol} / \mathrm{l})$ & 90 & 9.7 & 88 & 5.2 \\
\hline FFA (mEq/l) & $0.37 * *$ & 0.14 & $0.16^{* *}$ & 0.04 \\
\hline Cortisol (nmol/l) & 11.36 & 8.82 & 10.90 & 10.17 \\
\hline
\end{tabular}

${ }^{1} \mathrm{AU}=$ Arbitary units.

${ }^{2} \mathrm{WBC}=$ White blood cell count.

${ }^{3} \mathrm{ASAT}=$ Serum aspartate aminotransferase activity.

$* P<0.05$.

$* * P \leq 0.001$.

1. A smaller mixed model consisted of fixed effects for lactation (early or late), hours and their interaction, and random effects for cow and for each hour-specific measurement across cows. Cows were assumed to be independent of each other, but hours were assumed to be correlated with each other following an autoregressive correlation structure (AR1). Between-cow variation and between-hour correlation was assumed to be the same regardless of lactation.

2. A larger mixed model consisted of the same fixed and random effects, but here the between-cow variation and the between-hour correlation parameters were allowed to be different for early and late lactations.

When possible, fits for these two models were compared using a likelihood ratio test. When the fit for the larger model was significantly better, these results are reported. This is the case for FFA, PCV, urea, creatinine, cortisol, ASAT, and logNAGase. All estimates are calculated using the MIXED-procedure in SAS statistical software (SAS 2002, SAS Institute Inc., Gary, NC).

Normality assumption for the residuals was checked graphically. Due to skewed distributions logarithmic transformations of NAGase and SCC are presented. Additionally to the two models above, we also fitted the same models with $\mathrm{h} 0$ as a fixed cow specific covariate in the model, but results differed very little from the ones presented here.

\section{RESULTS}

Prechallenge values for serum and milk parameters were generally similar between cows in EL and LL

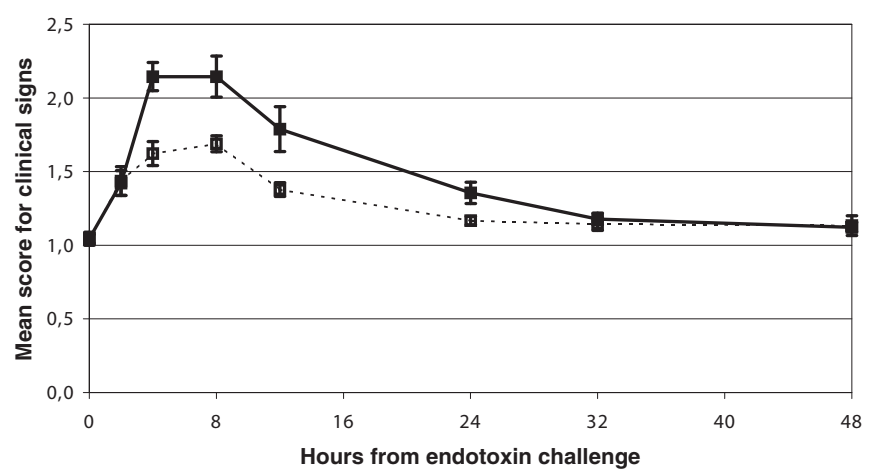

Figure 1. Changes in cows' response to endotoxin during the experiment. Data points represent the average ( \pm SE) of nine cows. Values in early lactation are marked with solid symbols and lines, and those in late lactation with open symbols and dashed lines.

(Table 1). Statistically significant differences were found only for serum urea, FFA concentrations, and milk yield.

Clinical signs of mastitis were seen in all cows at both times of challenge, although none of the cows had a severe response. In EL, one cow showed mild and nine cows moderate response, whereas in LL nine cows showed mild and one cow moderate response. The cow with mild response in EL and the cow with moderate response in LL showed similar responses also at the other challenge time. The difference in means between the cow's response in EL and LL was highly significant $(P<0.01)$ (Figure 1).

The peak in systemic signs, including elevated rectal temperature and heart rate, loss of appetite, and discomfort, occurred either at 4 or $8 \mathrm{~h}$ postchallenge (PC), varying between individuals and temporally. After $8 \mathrm{~h}$ PC, systemic signs started to decrease and were almost at baseline levels at $24 \mathrm{~h} \mathrm{PC}$ in both EL and LL (Figure 1). Local signs were most prominent in all cows at $4 \mathrm{~h}$ PC; the udder was swollen, hard, and tender, and some cows leaked milk. After $48 \mathrm{~h}$, the udder returned to normal. The first visible changes in milk of the challenged quarter appeared on average at $8 \mathrm{~h} \mathrm{PC}$ in EL and at $4 \mathrm{~h}$ PC in LL. In some cows, clots continued to be seen in the milk until the end of follow-up. Only mild changes in milk appearance occurred in the control quarters. Milk yield decreased in most cows on the first day after challenge, on average 18\% in EL and 35\% in LL. The milk yield returned back to baseline levels on the second day in EL and on the third day in LL.

In the endotoxin-infused quarter, milk SCC clearly started to increase already at $2 \mathrm{~h} \mathrm{PC}$, reaching an apex at 8 to $24 \mathrm{~h} \mathrm{PC}$ (Figure 2). At $12 \mathrm{~h}$ PC the value of milk SCC is missing, as the milk was too much changed to be reliably analyzed. Milk NAGase activity followed the increase of SCC, and peaked at $12 \mathrm{~h} \mathrm{PC}$ at 320 arbitrary 

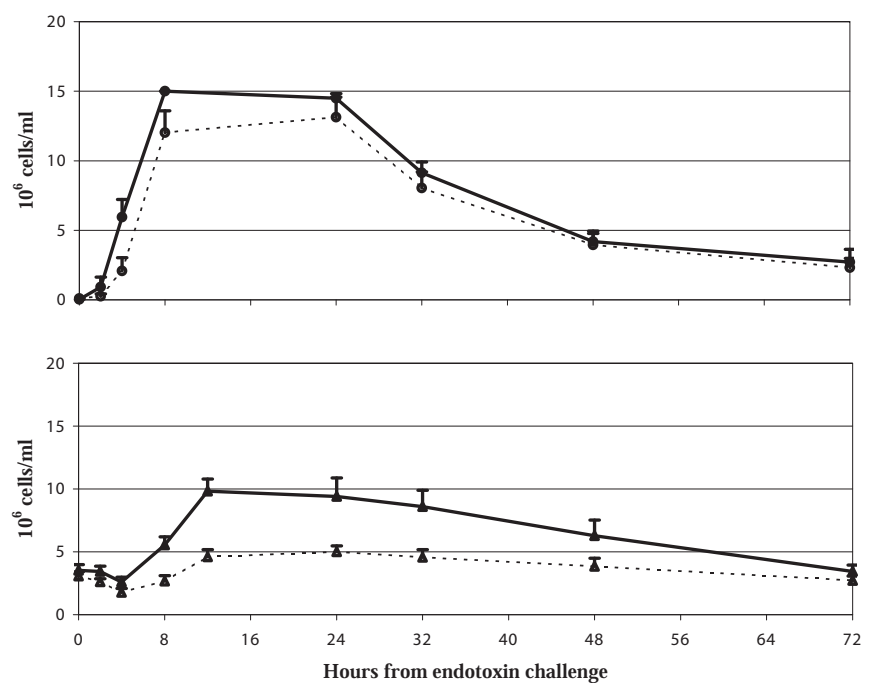

Figure 2. Changes in milk SCC (-) and blood neutrophil count $(\boldsymbol{\Delta})$ during the experiment. Data points represent the average $( \pm \mathrm{SE})$ of nine cows. Values in early lactation are marked with solid symbols and lines, and those in late lactation with open symbols and dashed lines.

units (AU) in EL and 269 AU in LL cows. The EL cows had significantly $(P<0.05)$ higher SCC than the LL cows. The NAGase levels were also higher in EL, although the difference was not statistically significant. SCC and NAGase did not return to baseline levels during the experimental period. Milk SCC and NAGase from the control quarters stayed in normal range in both EL and LL.

The number of blood neutrophils significantly changed during the experiment $(P<0.001)$, and differed between EL and LL cows $(P<0.01)$ (Figure 2). After 4 $\mathrm{h}$ PC, the neutrophil count increase was more pronounced in EL than in LL, remaining higher until 32 $\mathrm{h}$ PC. The same trend was seen in white blood cell count (WBC). At $4 \mathrm{~h} \mathrm{PC}, \mathrm{WBC}$ was its lowest, at $5.3 \pm 10^{9}$ cells/L in EL and $5.2 \pm 10^{9}$ cells/L in LL. The highest WBC, $13.3 \pm 10^{9}$ cells $/ \mathrm{L}$ and $9.4 \pm 10^{9}$ cells/L, was seen at $24 \mathrm{~h} \mathrm{PC}$ in EL and at $32 \mathrm{~h} \mathrm{PC}$ in LL, respectively. The difference in the average level of WBC between EL and LL was highly significant $(P<0.01)$. In addition the number of blood lymphocytes changed considerably during the experiment $(P<0.001)$. At 8 and $12 \mathrm{~h} \mathrm{PC}$, the number of lymphocytes was lower in EL than in LL. The PCV changed significantly $(P<0.001)$ during the experiment, but the values stayed within normal ranges (Carlson, 2002).

After endotoxin challenge the blood CL started to decrease in EL and increase in LL (Figure 3), whereas the milk CL increased in both EL and LL. The increase was more prominent in EL, although the differences were not statistically significant.
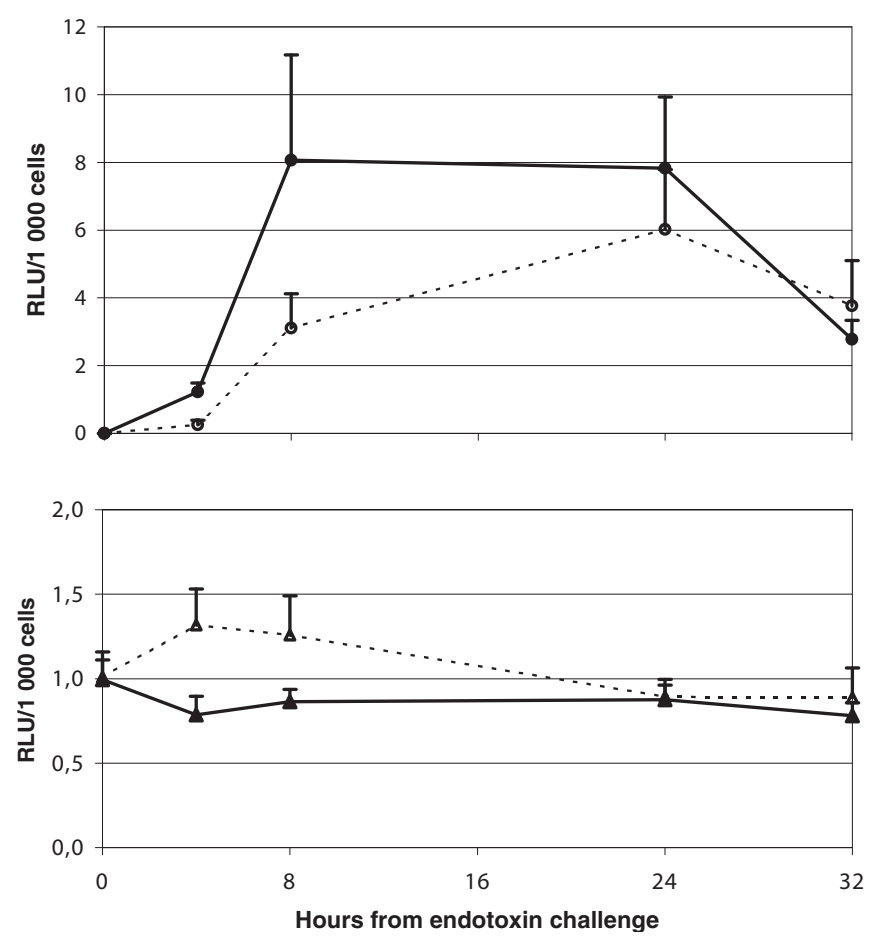

Figure 3. Changes in chemiluminescence of milk somatic cells ( ) and blood neutrophils ( $\mathbf{\Delta})$ during the experiments. Data points represent the average ( $\pm \mathrm{SE}$ ) of nine cows. Values in early lactation are marked with solid symbols and lines, and those in late lactation with open symbols and dashed lines.

The concentrations of serum FFA were significantly $(P<0.001)$ higher and serum urea significantly $(P<$ 0.05) lower in EL than in LL throughout the study (Figure 4). Serum cortisol changed significantly $(P<$ 0.001 ), reaching peak values at $4 \mathrm{~h} \mathrm{PC}$ (mean values $134.8 \mathrm{nmol} / \mathrm{L}$ in $\mathrm{EL}$ and $156.4 \mathrm{nmol} / \mathrm{L}$ in $\mathrm{LL}$ ) and re-

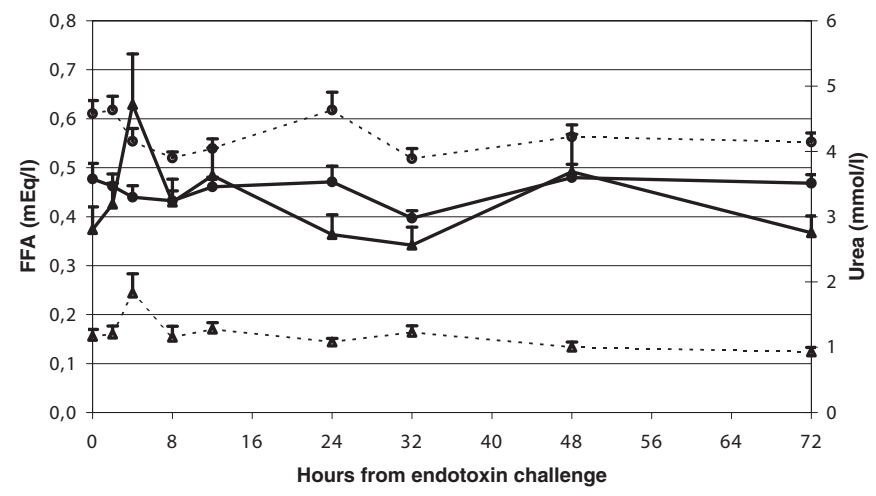

Figure 4. Changes in serum urea $(\bullet)$ and FFA $(\Delta)$ concentrations during the experiment. Data points represent the average $( \pm \mathrm{SE})$ of nine cows. Values in early lactation are marked with solid symbols and lines, and those in late lactation with open symbols and dashed lines. 
turning to baseline levels after $12 \mathrm{~h}$ PC. No significant differences were seen between the levels in EL and LL. Concentrations of serum urea, FFA, creatinine, and ASAT also showed significant $(P<0.001)$ changes, but the values stayed within the normal range (Carlson, 2002). The changes in blood $\mathrm{Ca}^{2+}$ levels were not significant.

\section{DISCUSSION}

Cows' responses, defined by local and systemic signs, to intramammarily infused $E$. coli endotoxin were significantly more severe in EL than in LL (Figure 1). The more severe response in EL has also been observed in experimental $E$. coli mastitis models (Hill et al., 1979; Shuster et al., 1996), which have, however, used different groups of cows over time. Our crossover study design diminished the interindividual variation (Pyörälä et al., 1994).

All animals responded rapidly to the endotoxin infusion, consistent with earlier studies (Hoeben et al., 2000a; Mehrzad et al., 2001a). Local signs were clearly seen at $2 \mathrm{~h} \mathrm{PC}$, and systemic signs at 4 to $8 \mathrm{~h}$ PC. Cows had similar local responses both in EL and LL, but systemic responses were more severe in EL. Both local and systemic signs are mediated by inflammatory mediators, such as $\mathrm{TNF} \alpha$ and interleukins, which are produced by macrophages in the mammary gland. Differences in their production and kinetics may cause variation in local and systemic signs (Hoeben et al., 2000a).

Total milk production decreased significantly after endotoxin infusion and returned to normal levels on the second day PC, as also reported by Hoeben et al. (2000a). This temporal decrease was more pronounced in LL, probably because some of the cows were actually drying out soon after the challenge. Parameters connected to the severity of the $E$. coli mastitis, including serum urea, creatinine, and ASAT (Cebra et al., 1996; Menzies et al., 2000) levels, showed some variation, but their clinical relevance may be negligible as the values remained within the normal range (Carlson, 2002). Serum urea concentration was, however, lower in EL than LL, and a low concentration in the periparturient period has been associated with subclinical ketosis (Jorritsma et al., 2001). The initial SCC was slightly lower in EL than in LL, but after the endotoxin induction, SCC increased faster in EL, agreeing with results from experimental E. coli mastitis (Shuster, 1996). Simultaneously with the increase in SCC in the milk, the number of circulating PMN in blood decreased, which is associated with PMN migration to the infection site (Paape et al., 1974). Both SCC and blood neutrophil numbers reached higher levels in EL than in LL cows. This could be due to greater PMN recruitment during EL, as had been shown in experimental $E$. coli mastitis (Shuster et al., 1996). The alterations from neutropenia to neutrophilia have been suggested to be caused by the excessive release of both mature and immature neutrophils from the bone marrow (Hoeben, 1999). In endotoxin mastitis, these changes are observed to appear and proceed earlier (Dosogne, 1998), and the proportion of immature neutrophils is smaller during neutrophilia, as the transformations have been supposed to result more from the release of reserve neutrophils from the marginal pool than from the increase in myelopoiesis (Hoeben, 1999).

The function of blood neutrophils after endotoxin induction, measured as CL, was different in EL and LL; it increased in LL but decreased in EL. The reason for decreased CL after parturition and during $E$. coli infections has been suggested to be an increased proportion of immature neutrophils (Dosogne, 1998), as these have been shown to have an impaired respiratory burst ability (Glasser and Fiederlein, 1987). In the endotoxin model, immaturity of PMN may not explain the decreased CL (Dosogne, 1998); in our study, low CL was seen simultaneously with neutropenia. In addition, the zymosan-induced CL measures not only the respiratory burst but also the capacity for phagocytosis (Hoeben, 1999), which is already present at an early stage of PMN maturation (Glasser and Fiederlein, 1987). The milk cells achieved higher CL than blood neutrophils, as also detected by Mehrzad et al. (2001a). The increase of milk CL in both EL and LL appeared at the same time as SCC increased. This increase was more pronounced in EL, occurring simultaneously with decreased CL in blood. This may be the result of an influx of the most active PMN from the circulation to milk.

No differences in cortisol values between EL and LL were present, even though the stress of parturition and the beginning of milk production are supposed to increase serum cortisol values around parturition (Breazile, 1988). This increase is anticipated to reduce the numbers and functions of neutrophils during the periparturient period (Breazile, 1988), but the effect on PMN phagocytosis capacity does not appear to be important (Dosogne, 1998). As also found previously (Paape et al., 1974; Shuster et al., 1993), cortisol peaked shortly after the endotoxin infusion, here the peak occurred at $4 \mathrm{~h} \mathrm{PC}$, at the same time as the number of circulating PMN in blood was lowest.

The FFA values were higher in EL than in LL throughout the experiment, which reflects the metabolic state of early lactation, characterized by fat mobilization and possible subclinical ketosis (Burvenich et al., 1994; Jorritsma et al., 2001). This has been suggested to interfere with neutrophil functions (Hoeben et al., 1997; Suriyasathaporn et al., 2000; Zerbe et al., 2000), and 
could be one reason for impaired CL of blood PMN seen in EL cows in this study.

Differences between EL and LL could be partly due to differences in production, function, and kinetics of cytokines. Endotoxin activates macrophages to produce cytokines, such as $\mathrm{TNF} \alpha$, which may have both stimulatory and inhibitory effects on PMN respiratory burst and phagocytosis (Dosogne, 1998). In the endotoxin mastitis model, $\mathrm{TNF} \alpha$ has been detected in the plasma of postpartum (Hoeben et al., 2000a) but not midlactation (Shuster et al., 1993) cows.

\section{CONCLUSIONS}

The more severe response after endotoxin induction seen in EL cows was accompanied by decreased function of blood PMN. The decreased function could be partly caused by the detected hyperketonemia, although the mechanism remains unclear. Cytokine production at the inflammation site could also be involved because cytokines affect both PMN functions and general clinical signs, and their release and kinetics may differ in EL and LL. Because their own defense mechanisms are impaired, early-lactating cows should be efficiently protected from $E$. coli infections.

\section{ACKNOWLEDGMENTS}

The authors would like to thank Satu Sankari for assistance with laboratory work, and Samuli Ripatti for excellent work with statistics.

\section{REFERENCES}

Breazile, J. E. 1988. The physiology of stress and its relationship to mechanisms of disease and therapeuthics. Vet. Clin. North Am. Food Anim. Pract. 4:441-480.

Burvenich C., M. J. Paape, A. W. Hill, A. J. Guidry, R. H. Miller, R. Heyneman, W. D. J. Kremer, and A. Brand. 1994. Role of the neutrophil leukocyte in the local and systemic reactions during experimentally induced $E$. coli mastitis in cows immediately after calving. Vet. Q. 16:45-50.

Carlson, G. P. 2002. Clinical chemistry tests. Pages 389-412 in Large Animal Internal Medicine. 3rd ed. B. P. Smith, ed. Mosby, Inc., St. Louis, MO.

Cebra, C. K., F. B. Garry, and R. P. Dinsmore. 1996. Naturally occurring acute coliform mastitis in Holstein cattle. J. Vet. Int. Med. 10:252-257.

Dosogne, H. 1998. Defense against intramammary Escherichia coli infections by bovine neutrophil leukocytes during the early postpartum period: phagocytosis and detoxification of endotoxins. $\mathrm{Ph}$. D. Diss., Gent Univ., Merelbeke, Belgium.

Dosogne, H., C. Burvenich, T. van Werven, E. Roets, E. N. Noordhuizen-Stassen, and B. Goddeeris. 1997. Increased surface expression of CD11b receptors on polymorphonuclear leucocytes is not sufficient to sustain phagocytosis during Escherichia coli mastitis in early postpartum dairy cows. Vet. Immunol. Immunopathol. 60:47-59.

Fabiny, D. L., and G. Ertigshausen. 1971. Automated reaction method for determination of serum creatinine with Centrifchem. Clin. Chem. 17:696-700.
Glasser, L., and R. L. Fiederlein. 1987. Functional differentiation of normal human neutrophils. Blood 69:937-944.

Gutmann, I., and H. U. Bergmeyer. 1974. Determination of urea with glutamate dehydrogenase as indicator enzyme. Pages 1794-1798 in Methods of Enzymatic Analysis. 2nd English ed. Vol. 4. H. U. Bergmeyer, ed. Academic Press, New York.

Hill, A. W., A. L. Shears, and K. G. Hibbit. 1979. The pathogenesis of experimental Escherichia coli mastitis in newly calved dairy cows. Res. Vet. Sci. 26:97-101.

Hirvonen, J., K. Eklund, A. M. Teppo, G. Huszenicza, M. Kulcsar, H. Saloniemi, and S. Pyörälä. 1999. Acute phase response in dairy cows with experimentally induced Escherichia coli mastitis. Acta Vet. Scand. 40:35-46.

Hoeben, D. 1999. Escherichia coli mastitis in postpartum cows: role of endotoxin and neutrophils with regard to the cows' metabolic and endocrine status and the use of drugs. Ph. D. Diss., Gent Univ., Merelbeke, Belgium.

Hoeben, D., C. Burvenich, E. Trevisi, G. Bertoni, J. Hamann, R. M. Bruckmaier, and J. W. Blum. 2000a. Role of endotoxin and TNFalpha in the pathogenesis of experimentally induced coliform mastitis in periparturient cows. J. Dairy Res. 67:503-514.

Hoeben, D., E. Monfardini, G. Opsomer, C. Burvenich, H. Dosogne, A. De Kruif, and J.-F. Beckers. 2000b. Chemiluminescence of bovine polymorphonuclear leucocytes during the periparturient period and relation with metabolic markers and bovine pregnancy-associated glycoprotein. J. Dairy Res. 67:249-259.

Hoeben, D., R. Heyneman, and C. Burvenich. 1997. Elevated levels of $\beta$-hydroxybutyric acid in periparturient cows and in vitro effect on respiratory burst activity of bovine neutrophils. Vet. Immunol. Immunopathol. 58:165-170.

International Dairy Federation. 1991. Recommended methods for somatic cell counting in milk. Page 5 in Laboratory Methods for Use in Mastitis Work. Int. Dairy Fed. Bull., ed. Int. Dairy Fed., Brussels, Belgium.

Jorritsma, R., H. Jorritsma, Y. H. Schukken, P. C. Bartlett, T. Wensing, and G. H. Wentink. 2001. Prevalence and indicators of post partum fatty infiltration of liver in nine commercial dairy herds in The Netherlands. Livest. Prod. Sci. 68:53-60.

Kehrli, M. E., B. J. Nonneche, and J. A. Roth. 1989. Alterations in bovine neutrophil function during the periparturient period. Am. J. Vet. Res. 50:207-214.

Lilius, E-M., and M. A. Waris. 1984. Very sensitive and rapid chemiluminescence method for the measurement of phagocytosis. Pages 401-404 in Analytical Applications of Bioluminescence and Chemiluminescence. R. C. Kricka, P. E Stanley, G. H. Thorpe, and T. P. Whitehead, ed. Academic Press, Orlando, FL.

Lindsey, J. K., ed. 1993. Models for Repeated Measurements. Ed. Oxford University Press, Oxford, UK.

Lojek, A., M. Ciz, P. Marnila, M. Duskova, and E-M. Lilius. 1997. Measurement of whole blood phagocyte chemiluminescence in Wistar rat. J. Biolum. Chemilum. 12:225-231.

Mattila, T., and M. Sandholm. 1986. Milk plasmin, I-acetyl- $\beta$-D-glucosaminidase and antitrypsin as determinants of bacterial replication rates in whey. J. Dairy Sci. 69:670-675.

Mehrzad, J., H. Dosogne, E. Meyer, and C. Burvenich. 2001a. Local and systemic effects of endotoxin mastitis on the chemiluminescence of milk and blood neutrophils in dairy cows. Vet. Res. $32: 131-144$

Mehrzad, J., H. Dosogne, E. Meyer, R. Heyneman, and C. Burvenich. 2001b. Respiratory burst activity of blood and milk neutrophils in dairy cows during different stages of lactation. J. Dairy Res. 68:399-415.

Menzies, F. D., S. H. McBride, S. W. J. McDowell, M. A. McCoy, W. McConnell, and C. Bell. 2000. Clinical and laboratory findings in cases of toxic mastitis in cows in Northern Ireland. Vet. Rec. $147: 123-128$.

Paape, M. J., W. D. Schultze, C. Desjardins, and R. H. Miller. 1974. Plasma corticosteroid, circulating leukocyte and milk somatic cell responses to Escherichia coli endotoxin-induced mastitis. Proc. Soc. Exp. Biol. Med. 145:553-559. 
Pyörälä, S., L. Kaartinen, H. Käck, and V. Rainio. 1994. Efficacy of two therapy regimes for treatment of experimentally induced Escherichia coli mastitis in the bovine. J. Dairy Sci. 77:453-461.

Pyörälä, S., and E. Pyörälä. 1998. Efficacy of parenteral administration of three antimicrobial agents in treatment of clinical mastitis in lactating cows: 487 cases (1989-1995). JAVMA 212:407-412.

Scandinavian Society for Clinical Chemistry and Clinical Physiology. 1974. Recommended methods for the determination of four enzymes in blood. Scan. J. Clin. Lab. Inv. 33:291-306.

Shuster, D. E., M. E. Kehrli, and M. G. Stevens. 1993. Cytokine production during endotoxin- induced mastitis in lactating dairy cows. Am. J. Vet. Res. 54:80-85.
Shuster, E., E. K. Lee, and M. E. Kehrli. 1996. Bacterial growth, inflammatory cytokine production, and neutrophil recruitment during coliform mastitis in cows within ten days after calving, compared with cows at midlactation. Am. J. Vet. Res. 11:15691575.

Suriyasathaporn, W., C. Heuer, E. N. Noordhuizen-Stassen, and Y. H. Schukken. 2000. Hyperketonemia and the impairment of udder defence: A review. Vet. Res. 31:397-412.

Zerbe, H., N. Schneider, W. Leibold, T. Wensing, T. A. M. Kruip, and H. J. Schuberth. 2000. Altered functional and immunophenotypical properties of neutrophilic granulocytes in postpartum cows associated with fatty liver. Theriogenology 54:771-786. 